\title{
Creating a "one-stop shop" for all the most interesting findings from across the field of andrology-Asian Journal of Andrology launches Research Highlights
}

\author{
Yi-Fei Wang \\ Editor-in-Chief, Asian Journal of Andrology \\ Asian Journal of Andrology (2010) 12: 619. doi: 10.1038/aja.2010.106
}

Thumbing the pages of various scientific journals a researcher might wonder: how do I efficiently and accurately identify articles that invoke my enthusiasm while informing me of important breakthroughs across the field of andrology? Skimming through an interesting article: how do I thoroughly and incisively comprehend the significance of the findings? Closing the article pages: how do I integrate the conclusions derived from the findings into my own research? Asian Journal of Andrology (AJA) would like to provide you an efficient information platform to address these questions through a brand new article type- - Research Highlights.

Starting in this September issue, Research Highlights will launch, providing a one-stop shop where our readers can get a digest of the most interesting and state-of-the-art primary research papers that relate to and inspire male health research. Experts in the field are invited to deliver brief updates on new progress, presenting their views in an approachable and influential style that is designed to be of interest to researchers and doctors from across the andrological sciences.

A good start is half way to success. In this September issue, Research Highlights from Prof. Getzenberg [1], Prof. Zitzmann [2] and Prof. Hellstrom [3] serve up wonderful hors d'oeuvres on some of the most recent ground-breaking discoveries in the fields of prostate cancer, late onset hypogonadism research and erectile dysfunction drug use investigation, respectively. We sincerely hope our readers will enjoy these pieces. Bon appetit!

We hope that Research Highlights, with their timely publication, insightful viewpoints and accessible writing, will better serve our readership, together with our other newly launched article types*, through providing insightful comments and discussions about all aspects of andrological research.

After experiencing this one-stop shop, please do not hesitate to flag to us any interesting developments you come across in the research literature as the basis for Research Highlights in the future. We are always pleased to engage our readership in our quest to provide a comprehensive digest of the current developments in the field!

\section{References}

1 Getzenberg RH. Novel approaches for the molecular classification of prostate cancer. Asian J Androl 2010; 12: 620-2.

2 Zitzmann M. Testosterone deficiency and treatment in older men: definition, treatment, pitfalls. Asian J Androl 2010; 12 : 623-5.

3 Hellstrom WJG. Does erectile dysfunction drug use contribute to risky sexual behavior? Asian J Androl 2010; 12: 626-7.

*Commentary articles comment on articles published in AJA with interesting findings.

Perspectives articles present personal, forward-looking or speculative, reviews of a scientific topic. Papers presenting controversial positions or two reviews that advocate opposite sides of a research controversy are also published as Perspectives.

Opinion pieces cover a wide variety of topics that are of current interest in andrology and highlight their interaction with society. They may discuss policy, ethics, science or society and should be written in an accessible, non-technical style as well as with authority, color, vivacity and personal voice. 